\title{
A TEORIA DA JUSTIÇA DE JOHN RAWLS APLICADA À HISTÓRIA DE BENNET OMALU: REFLEXÕES SOBRE UM CASO RECENTE E SEU DISTANCIAMENTO DO IDEAL FILOSÓFICO DE RAWLS \\ THE JOHN RAWLS THEORY OF JUSTICE APPLIED TO BENNET OMALU STORY: THOUGHTS ON A CURRENT CASE AND ITS DISCONNECTION TO RAWLS' PHILOSOPHIC IDEAL
}

\author{
${ }^{1}$ Tainá Camargo
}

\section{RESUMO}

Em 2015, foi lançado o filme Concussion, que conta a história real de Bennet Omalu, um legista que atuava na cidade de Pittsburgh. Ao realizar a autópsia de um ídolo do futebol americano, Omalu identificou uma doença nunca antes diagnosticada que pode ser causada pela prática de futebol americano e iniciou uma batalha contra a liga de futebol mais poderosa do mundo, a National Football League. A história é analisada neste trabalho com base na Teoria da Justiça de John Rawls, com reflexões sobre o porquê, mesmo em uma sociedade desenvolvida, existem casos de absoluto afastamento do seu ideal filosófico.

Palavras-chave: Neuropatologia, Teoria da justiça, Futebol, Concussões

\begin{abstract}
In 2015, was launched the movie Concussion which tells the true story of Bennet Omalu - a medical examiner who worked in the city of Pittsburgh. When performing the autopsy of an idol of football, Omalu identified a never before diagnosed disease that can be caused by football practice and started a battle against the most powerful football league in the world, the National Football League. The story is reviewed in this study based on the John Rawls' Theory of Justice, with reflections on why, even in a developed society, there are cases of absolute disconnection of his philosophical ideal.
\end{abstract}

Keywords: Neuropathology, A theory of justice, Football, Concussions

\footnotetext{
${ }^{1}$ Mestranda em Direito pela UERJ Universidade do Estado do Rio de Janeiro, RIo de Janeiro (Brasil) E-mail: tahuttenc@gmail.com
} 


\section{Introdução}

Bennet Omalu é um nigeriano que vive nos Estados Unidos, exercendo as atividades de legista e pesquisador na área das neurociências. No âmbito de sua atuação profissional, Omalu foi o primeiro a identificar, descrever e nomear uma grave doença que acomete os jogadores de futebol americano, a "Chronic Traumatic Encephalopathy (CTE)" ou Encefalopatia Traumática Crônica (ETC), travando uma dura batalha com a National Football League (NFL) - liga de futebol americano dos Estados Unidos que é a mais rica e influente liga de futebol americano do mundo ${ }^{2}$.

A história da descoberta científica de Bennet Omalu e como tal descoberta abalou os pilares da NFL deram origem ao artigo "Bennet Omalu, Concussions, and the NFL: How One Doctor Changed Football Forever", escrito por Jeanne Marie Laskas e publicado na revista americana GQ em 14 de setembro de 2009.

O artigo acima mencionado foi transformado posteriormente no livro Concussion (lançado pela editora Penguin Random House no ano de 2015), e adaptado para um filme de nome idêntico, em inglês - ou, traduzido para o português, "Um Homem entre Gigantes" -, dirigido por Peter Landesman e estrelado pelo ator norte-americano Will Smith. A produção do filme levou à criação do Instituto Bennet Omalu Patologia, que realiza pesquisas avançadas sobre concussões.

A história do filme é assim resumida nas sinopses:

Dr. Bennet Omalu, neuropatologista forense, diagnostica um severo trauma cerebral em um jogador de futebol americano e, investigando o assunto, descobre se tratar de um mal comum entre os profissionais do esporte. Determinado a reverter o quadro e expôr para o mundo a grave situação, ele trava uma guerra contra a poderosa NFL.

Como se pode observar, o cientista, após descobrir uma doença comum aos jogadores de futebol americano, resolveu levar tal conhecimento a todos e surpreendentemente verificou que a NFL (e grande parte da sociedade norte-americana) não estava preparada para assumir que o futebol pudesse causar mal irreparável a seus jogadores.

Em sua busca por levar informação aos demais, Omalu enfrentou (e continua enfrentando) diversas resistências, inclusive por parte da comunidade médica, tendo sido obrigado inclusive a custear as pesquisas com seus próprios recursos.

\footnotetext{
${ }^{2}$ Estima-se que as receitas da NFL alcancem aproximadamente US\$ 10 bilhões por ano e o valor agregado dos times que compõem tal liga sejam de aproximadamente US\$ 46 bilhões. Fonte: Bloomberg, 2014. Disponível em http://www.bloomberg.com/news/articles/2014-09-12/the-nfl-could-be-a-big-business-with-puny-revenue. Acesso em: 20 mar. 2016.
} 
A situação traz reflexões diversas em relação aos preceitos éticos e filosóficos dos envolvidos e leva ao espectador (ou leitor) discussões entre os personagens que o remetem às indagações feitas outrora por John Rawls.

Assim, o presente trabalho busca analisar tais preceitos e discussões, com base na Teoria da Justiça de John Rawls, de modo a responder ao seguinte problema: por que sociedades consideradas desenvolvidas ainda se deparam com situações gravemente injustas?

A pesquisa, portanto, se justifica, uma vez que é de suma importância compreender o comportamento humano diante da descoberta de uma situação injusta, principalmente se se considerar que esse comportamento ocorre em uma sociedade economicamente desenvolvida, na qual viveu o próprio John Rawls.

A metodologia científica empregada é a indutiva, pois parte-se da análise da realidade vivida por Bennet Omalu para alcançar elaborações genéricas acerca das relações sociais na atualidade.

Assim, busca-se avaliar em que medida o ser humano é capaz de reconhecer seus erros e em que medida instituições como a NFL estão dispostas a cooperar para melhorar a qualidade de vida da população.

Para tanto, o trabalho se divide em duas partes: a primeira, descritiva e narrativa - que descreve os personagens envolvidos e situações interessantes da história de Bennet Omalu, a segunda, que retoma conceitos abordados pela Teoria da Justiça de John Rawls e os relaciona com os aspectos descritos na parte anterior, respondendo ao problema apresentado e tecendo comentários que auxiliam a chegar às conclusões.

Neste sentido, o principal objetivo deste trabalho é fazer ponderações de cunho filosófico e ético acerca de uma história real e recente, especialmente com base na Teoria da Justiça de John Rawls, buscando soluções para o problema apresentado.

\section{Primeira Parte: a história de Bennet Omalu, o homem entre gigantes}

Antes de narrar e analisar a trama em que se envolveu Bennet Omalu, é importante descrever, ainda que brevemente, a história precedente e as características dos personagens principais, uma vez que os traços culturais, acadêmicos, pessoais e profissionais de cada um são fundamentais para as reflexões filosófico-jurídicas feitas ao longo do trabalho, pois permitem análise contextualizada das condutas praticadas e dos cenários narrados. 


\subsection{Descrição dos personagens principais}

Como se verá adiante, será feita a descrição dos dois principais personagens da história ora narrada, Dr. Bennet Omalu e Michael Lewis Webster, posto que todo o enredo se desenvolve em torno de suas histórias pessoais.

\subsubsection{Bennet Omalu}

Bennet Omalu nasceu em Nnokwa, no sudeste da Nigéria, em setembro de 1968. Seu sobrenome, Omalu, é uma abreviação de "Onyemalukwube", que significa que "se um homem sabe algo, ele deve falar". Como será narrado adiante, a cultura de Omalu e o significado de seu sobrenome foram fatores importantes para que ele tivesse dado seguimento ao seu trabalho durante o período em que enfrentou a NFL.

Omalu graduou-se na Universidade da Nigéria em 1991. Em 2004, recebeu o título de mestre em saúde pública na área de epidemiologia pela Universidade de Pittsburgh. Ele também recebeu o título de mestre em administração de negócios (Master in Business Administration) pela Universidade Carnegie Mellon em 2008. Omalu possui certificações em Anatomia Patológica, Patologia Clínica, Patologia Forense e Neuropatologia. Atualmente, é médico examinador chefe de San Joaquin County, Califórnia, e presidente do Instituto Bennet Omalu Patologia.

Em sua carreira, Dr. Omalu prestou depoimentos no Congresso Nacional dos Estados Unidos e deu testemunhos diversos, enquanto especialista, em casos julgados pelas cortes federais e estaduais dos Estados Unidos.

Profundamente religioso e completamente absorvido pelos estudos e atividades profissionais, Omalu é tido como excêntrico pelos demais, não só pelo cuidado e profundidade das autópsias realizadas, como por "conversar" com os corpos que analisa. Ele próprio se declara como um defensor dos mortos, alguém que teria o encargo de defender e falar com aqueles que já tivessem partido.

Apesar de ter vivido mais de 30 (trinta) anos em Pittsburgh, uma cidade apaixonada por futebol americano, Dr. Omalu sequer havia assistido a um jogo até o seu "encontro" com Mike Webster, o próximo personagem a ser descrito ${ }^{3}$.

\footnotetext{
${ }^{3}$ Em entrevista concedida ao Public Broadcasting Service, Omalu declarou: "See, I grew up in Africa, in Nigeria. I never knew, I never had any reasonable encounter with football. I saw football on Sky News. I though there were people dressed like extraterrestrials, you know, like they were going to Mars or something, headgears and shoulder pads". Disponível em: http://www.pbs.org/wgbh/pages/frontline/sports/league-of-denial/the-frontline-interview-drbennet-omalu/. Acesso em: 12 mar. 2016
} 


\subsubsection{Mike Webster}

Michael Lewis Webster (Mike Webster) era um jogador de futebol americano que ocupava posição central (center) nas equipes do Pittsburgh Steelers e Kansas City Chiefs. Apelidado de "Iron Mike", Mike Webster atuou na linha ofensiva do Pittsburgh Steelers durante quatro vitórias de tal equipe no campeonato "Super Bowl" entre os anos de 1974 e 1979, tendo sido considerado um dos melhores centrais da história da NFL e entrando para o hall da fama do esporte.

Em 1990, Mike Webster aposentou-se, com um total de 245 (duzentos e quarenta e cinco) jogos em que jogou como central. Não é exagero dizer que Webster era tido como herói para muitos. Um verdadeiro ícone do futebol americano. Entretanto, estima-se que "Iron Mike" tenha sofrido aproximadamente 25.000 (vinte e cinco mil) colisões violentas durante sua carreira.

Infelizmente, após sua aposentadoria, Webster apresentou sinais de demência, amnésia, depressão, fraqueza óssea e dores musculares. Em seus últimos anos de vida, Mike Webster, que já havia perdido todo o seu patrimônio, passou a viver dentro de um carro, com uma das janelas quebradas, dormindo em posição fetal e em estado totalmente catatônico.

Em razão dos seus sintomas, em 1997, Webster procurou o advogado Fitzsimmons para pedir ajuda. Na visita ao advogado, Mike Webster contou que não conseguia lembrar quase nada de sua vida. Ele imaginava já ter visitado diversos advogados e médicos, mas não possuía memória de quem seriam eles. Sequer sabia se estava casado ainda - possuía apenas vaga memória de ter se divorciado e do remédio que tomava em grandes quantidades, a ritalina.

$\mathrm{Na}$ qualidade de advogado especializado em responsabilidade civil (personal injury), Fitzsimmons percebeu que o caso de Webster era obviamente de um homem que sofria de danos cerebrais, conhecidos nos Estados Unidos como "closedhead injury", bastante comuns em pessoas que sofrem acidentes de carro. Nesses tipos de lesões, não há fratura exposta nem sinais de danos físicos ao crânio, mas aparentes problemas psiquiátricos como perda de memória, mudança de personalidade e comportamento agressivo.

Durante um ano e meio, Fitzsimmons procurou registros médicos de Webster e o submeteu a quatro avaliações médicas. Todas confirmaram que Mike Webster sofrera danos cerebrais em virtude de múltiplas concussões. Assim, Fitzsimmons protocolou, em nome de Webster, perante a NFL, pedido de indenização por invalidez. 
Apesar dos diversos graus de invalidez considerados pela NFL, Mike Webster foi indenizado como se tivesse o grau mais leve, passando a perceber uma indenização mensal de apenas US\$ 3,000.00 (três mil dólares). O advogado ainda tentou reclamar, embasado nos quatro idênticos diagnósticos que obtivera - inclusive um do médico da própria NFL -, mas, no fim, a NFL recusou-se a rever a indenização.

Indignado, Fitzsimmons apelou à Corte Distrital de Baltimore, conseguindo reversão da decisão da NFL (a primeira vez na história), mas a NFL recorreu à corte federal que decidiu que Mike Webster não se qualificava como completamente inválido, mantendo a decisão inicial da NFL ${ }^{4}$.

Mike Webster faleceu em setembro de 2002, com apenas 50 (cinqüenta) anos, supostamente vítima de um ataque cardíaco, como inicialmente divulgado. No entanto, a verdadeira causa de sua morte acabou não sendo divulgada pelo hospital no qual faleceu - por solicitação da própria família, segundo informado pelo hospital. Como se narrará adiante, é a partir de sua morte que Mike Webster "se encontra" com o Dr. Omalu e inicia-se a história central deste trabalho.

\subsection{A descoberta de Bennet Omalu}

Em uma manhã de um sábado, setembro de 2002, Bennet Omalu deparou-se com um inusitado fato: deveria fazer a autópsia de um dos principais nomes do futebol americano da cidade de Pittsburgh, Mike Webster. Obviamente, o falecimento de Iron Mike estava sendo noticiado em todos os canais de comunicação e chamava a atenção de todos os moradores da cidade, mas Dr. Omalu não fazia ideia da importância do "paciente"5.

Ao entrar na sala de autópsias, Omalu procedeu de maneira usual, apesar dos apelos para que "deixasse Mike Webster em paz". Fez todos os cortes necessários no corpo, até chegar ao crânio e, consequentemente, acessar o cérebro, apesar dos comentários de que não havia necessidade, já que, supostamente, a morte havia sido causada por parada cardíaca ${ }^{6}$.

Em seu artigo, Laskas narra assim os primeiros pensamentos investigativos de Omalu:

\footnotetext{
${ }^{4}$ Em 13 de dezembro de 2006, quatro anos após o falecimento de Mike Webster, a Corte de Apelação NorteAmericana, reconheceu que Webster estava total e permanentemente inválido em virtude dos danos cerebrais causados pelos traumas sofridos durante os jogos de futebol americano e condenou a NFL a pagar mais de US\$1,500,000.00 (um milhão e quinhentos mil dólares) aos filhos e ex-esposa de Webster.

${ }^{5}$ Em entrevista concedida ao Public Broadcasting Service, Omalu declarou: "(...) and I go tinto the office, and I asked, "What is going on?" One the technicians said, "Oh, Mike Webster was on the table." So I said, "Who is Mike Webster?" and everybody looked at me like: "Where is he from? Is he from outer - who is this guy who doesn't known Mike Webster in Pittsburgh". Disponível em: http://www.pbs.org/wgbh/pages/frontline/sports/league-of-denial/thefrontline-interview-dr-bennet-omalu/. Acesso em: 12 mar. 2016

${ }^{6}$ Apesar da parada cardíaca, constava na certidão de óbito de Webster informação de que síndrome pós-concussão havia sido fator de contribuição para a morte. Tal informação faz com que a morte seja qualificada como acidental e, portanto, outorga competência ao legista para averiguar a causa da morte.
} 
Omalu stared at Mike Webster's brain. He kept thinking, How did this big athletic man end up so crazy in the head? He was thinking about football and brain trauma. The leap in logic was hardly extreme. He was thinking, Dementia pugilistica? "Punchdrunk syndrome," they called it in boxers. The clinical picture was somewhat like Mike Webster's: severe dementia-delusion, paranoia, explosive behavior, loss of memory-caused by repeated blows to the head. Omalu figured if chronic bashing of the head could destroy a boxer's brain, couldn't it also destroy a football player's brain? Could that be what made Mike Webster crazy? (LASKAS, 2009, p. 03)

Como visto acima, apesar de não ter encontrado dano aparente ao cérebro de Webster, Omalu resolveu investigar mais. Por isso, pediu autorização especial ao seu supervisor, o patologista Cyril Wecht, para proceder com análises que não faziam parte do protocolo ordinário da clínica e que, portanto, não possuíam destinação orçamentária para serem feitas. Wecht, famoso por não se intimidar em casos como esses (ele havia examinado famosos como John Kennedy e Elvis Presley), concedeu a autorização que Omalu solicitara.

Após semanas sem encontrar nada, Omalu passou a ter que custear as pesquisas com seus próprios recursos ${ }^{7}$. Mergulhado nas análises dia e noite, finalmente Omalu encontrou algo: manchas marrons e vermelhas por todo o cérebro, grande acumulação de proteínas tau - as quais, quando defeituosas, se aglomeram e causam disfunções nos neurônios, como a doença de Alzheimer e o Parkinson, podendo afetar o humor e a emoção -. Esta era a causa da loucura de Mike Webster.

Omalu mostrou sua descoberta para o Sr. Wecht e para cientistas da Universidade de Pittsburgh. Todos concordaram que o achado era uma doença não identificada. Assim, Omalu a nomeou de "Chronic Traumatic Encephalopathy (CTE)" ou Encefalopatia Traumática Crônica (ETC) e escreveu, em coautoria com o Sr. Wecht e os demais cientistas da Universidade de Pittsburgh, o artigo científico "Chronic Traumatic Encephalopathy in a National Football League Player". Em julho de 2005, o artigo foi publicado em uma revista de prestígio na área médica.

Até aquele momento, Omalu acreditava que a comunidade médica e a NFL ficariam gratos com sua descoberta, uma vez que, na sua opinião, a evidência científica que acabara de comprovar permitiria buscar a cura para a doença. Nessa época, Omalu chegou a escrever uma carta para a NFL sugerindo uma parceria para que fizessem um profundo estudo e tentassem buscar respostas e soluções. Entretanto, o oposto ocorreu.

Como se verá adiante, as repercussões da descoberta de Omalu foram tão negativas que, em muitos momentos, ele preferiu nunca ter se deparado com o corpo de Mike Webster.

\footnotetext{
${ }^{7}$ Estima-se que Omalu tenha despendido aproximadamente US\$ 100,000.00 (cem mil dólares), conforme informações divulgadas por Laskas (LASKAS, 2009).
} 
Como ele mesmo declarou em entrevista concedida ao Washington Post": "If my faith had not been strong, I believe I would have committed suicide. I was so alone. I lost my job. But it is that great American spirit that the truth is prevailing".

\subsection{As repercussões da descoberta}

Após a publicação do artigo de Omalu, o Comitê de Traumas ao Cérebro da NFL enviou carta ao editorial pedindo que se retratasse. Na carta, ataques a Omalu eram aparentes, como, por exemplo, "We own this field. We are not going to bow to some no name Nigerian with some bullshit theory" (LASKAS, 2009, p. 08 e 09).

Ao contrário do que a NFL esperava, sua conduta perante a descoberta de Omalu não o fez desistir. Quando recebeu a carta acima mencionada, Omalu já tinha autorização para iniciar pesquisas em um segundo cérebro, o cérebro do jogador de futebol americano Terry Long, que falecera aos 45 (quarenta e cinco) anos de idade.

A história clinica de Terry Long era muito similar a de Mike Webster: depressão, perda de memória, comportamento louco e insolvência. As análises clínicas do seu cérebro confirmaram que as semelhanças com Mike Webster tinham a mesma origem: manchas e aglomerações de proteínas tau - achados pouco comuns em pessoas de apenas 45 (quarenta e cinco) anos ${ }^{9}$.

Com base nas pesquisas envolvendo Terry Long, Omalu escreveu um novo artigo, “Chronic Traumatic Encephalopathy in a National Football League Player: Part II” e o enviou para a mesma revista que, a despeito da NFL, resolveu publicá-lo - deixando claro que não ia se retratar pela publicação do primeiro artigo.

A repercussão do segundo artigo foi ainda pior. A notícia de que atletas aposentados possivelmente sofreriam debilitações mentais atingiu as manchetes. A NFL, por sua vez, reforçou os ataques à Omalu. Seus amigos o alertaram: "You are challenging one of the most powerful organizations in the world. There may be other things going on that you're not aware of. Be careful!"' (LASKAS, 2009, p. 10).

No meio aos ataques, Omalu recebeu então uma ligação de Julian Bailes, norteamericano, neurocirurgião de renome que trabalhara por décadas com o time dos Steelers (do qual Mike Webster fazia parte) e que atuava como diretor da neurocirurgia do Hospital Universitário de West Virginia. Essa ligação mudou o rumo da sua batalha.

${ }^{8}$ OMALU, B. Entrevista concedida ao Washington Post. Washington, EUA, 29 dez. 2016. Disponível em: https://www.washingtonpost.com/news/to-your-health/wp/2015/12/29/bennet-omalu-doctor-who-raised-alarm-bellsabout-nfl-head-injuries-on-racism-in-u-s-science/. Acesso em: 20 mar. 2016.

${ }^{9}$ Segundo Omalu, "This looks more like a 90 year old brain with advanced Alzheimer's" (LASKAS, 2009, p. 09). 
Julian Bailes era amigo de Mike Webster e também conhecia Terry Long. Bailes estava liderando um estudo para o Centro de Estudos de Atletas Aposentados da Universidade da Carolina do Norte sugerindo uma ligação entre as concussões sofridas e a depressão. Ele acreditava em Omalu e resolveu ajudá-lo.

A pedido de Omalu, Bailes o levou para conversar com um médico de renome ligado à NFL. Entretanto, os dois não só não se entenderam, como tal médico, ao discutir com Omalu, disse que o reconhecimento da ligação entre a prática do futebol americano e a doença poderia acabar com uma indústria que traz muitos benefícios sociais como doações a instituições de caridade e geração de empregos. Isto é, o sofrimento dos jogadores seria compensado com todos os benefícios que o esporte traria à sociedade.

A discussão, encenada no filme Concussion, não acabou bem. Omalu ficou indignado com a proposta do médico - encerrar as pesquisas e nada mais publicar, para preservar os benefícios sociais trazidos pelo futebol americano -, e os dois não chegaram a nenhum acordo.

Além de Bailes, Fitzsimmons, o advogado que ajudara Webster, também decidiu colaborar. Omalu, Bailes, Fitzsimmons e um quarto cientista, Chris Nowinski ${ }^{10}$, criaram então uma organização, a Sports Legacy Institute, para estudar o ETC.

Nesse contexto, os membros do instituto iniciaram as pesquisas em um terceiro cérebro, o do jogador Andre Waters para quem a NFL havia negado pagamento de plano de aposentadoria apesar das numerosas concussões, dores constantes e forte depressão. Em 20 de novembro de 2006, aos 44 (quarenta e quatro) anos de idade, Andre Waters havia se suicidado com um tiro na boca.

As amostras clínicas de Waters confirmaram mais um caso de ETC. O quarto caso confirmado de ETC foi de alguém ainda mais jovem, o jogador Justin Strzelczyk, que falecera aos 36 (trinta e seis) anos em um grave acidente de carro, a quase $150 \mathrm{~km} / \mathrm{h}$ (cento e cinquenta quilômetros por hora), por achar que estava sendo perseguido por demônios.

Omalu se perguntava se os quatro casos tinham algo de especial - teriam tomado drogas ou esteróides, por exemplo. Bailes e Fitzsimmons tinham a desconfiança de que a doença possivelmente afetava todos (ou quase todos) os jogadores.

Nesse contexto de novas descobertas, a NFL começou a ceder e a história chegou a uma nova fase, como será narrado adiante.

\footnotetext{
10 Nowinski não era, na realidade, um cientista. Ele era lutador de wrestling pela universidade de Harvard. Aos 24 anos, sofrendo perda de visão, perda de equilíbrio e problemas de memória, ele procurou ajuda a oito médicos que não souberam dizer o que ele tinha. E o que ele tinha, na realidade, eram concussões. E a ausência de informação acabava permitindo que ele voltasse às lutas e agravasse ainda mais seu quadro. Quando Nowinski finalmente encontrou a descoberta de Omalu, interessou-se pela causa e escreveu o livro Head Games: Football's Concussion Crisis, que o colocou no centro da mídia - e, consequentemente, no centro da história do ETC.
} 


\subsection{O final da história}

Em 2007, a NFL fez uma conferência que seria a chance para discutirem a ETC. Foram convidados diversos cientistas independentes. Bailes foi convidado para apresentar o trabalho desenvolvido. Omalu não. Evidentemente, a NFL não queria alguém que nunca tivesse tido relação com a NFL tratasse de um assunto tão importante. A intenção era marginalizar Omalu.

Naquele momento, a NFL já tinha tido algum progresso em admitir o problema das concussões: havia anunciado um estudo que envolveria uma bateria de testes clínicos em 120 (cento e vinte) jogadores e havia criado um plano de aposentadoria de até US\$ 88,000.00 (oitenta e oito mil dólares) ${ }^{11}$.

Apesar disso, a NFL não havia assumido qualquer responsabilidade pela doença. Pelo contrário, seu comitê publicava artigos científicos argumentando que repetidas colisões na cabeça não provocavam danos cerebrais e alguns de seus médicos insistiam em negar as descobertas de Omalu repetindo incansavelmente que não haviam evidências concretas de que a ETC manifestava-se em jogadores de futebol americano.

Diante da resistência da NFL, Omalu e os demais mantiveram suas pesquisas, acharam outras evidencias médicas e as mantiveram silentes ${ }^{12}$. Haviam desistido de mostrar ao mundo que a ETC era uma doença grave que acometia os jogadores de futebol americano. Nowinski, no entanto, não estava convencido de que deveriam ficar quietos.

Nowinski levou as pesquisas para a Escola de Medicina da Universidade de Boston, onde foi criado o centro para estudos de encefalopatia traumática, diagnosticando mais casos de ETC e iniciando o registro de aproximadamente 100 (cem) atletas que concordavam em doar seus cérebros para estudos, após suas mortes. Nowinski levou os casos a público como se fossem pesquisas do centro da Universidade de Boston (inclusive aqueles descobertos por Omalu). Apesar de indignado com a postura de Nowinski, Omalu nada fez.

Já vivendo na Califórnia, onde assumiu o cargo de médico examinador chefe do San Joaquin County, como anteriormente mencionado, Omalu manteve com Fitzsimmons e Bailes um grupo de estudos para continuar os trabalhos contra danos cerebrais, o The Brain Injury

\footnotetext{
${ }^{11}$ O plano fora criado após a NFL ter recebido uma carta escrita por Sylvia Mackey, esposa do jogador John Mackey, em que ela demonstrava o horror que estava vivendo e como os US\$ 2,450.00 (dois mil, quatrocentos e cinqüenta dólares) por mês eram insuficientes para cobrir as despesas que tinham.

${ }^{12}$ Além da negação por parte da NFL, Omalu era alvo freqüiente de ameaças (especialmente de fãs de futebol americano que acreditavam que a descoberta de Omalu extinguiria o esporte). Até mesmo a esposa de Omalu sofrera
} 
Group, que recebeu patrocínio de US\$30,000,000.00 (trinta milhões de dólares) do Blanchette Rockefeller Neurosciences Institute ${ }^{13}$.

O grupo passou, então, a buscar a cura para o ETC: "You pop a pill before you play, a medicine that prevents the buildup of tau," disse Omalu, completando em seguida:

Like you take an aspirin to prevent heart disease. This is how we now need to talk. Not this backandforth of human selfishness. Not this NFL politics and meanness. Anybody still denying the disease is out of his mind. The issue now is treatment. That is my next step, now that I understand the pathology. (LASKAS, 2009, p. 20)

A NFL, no entanto, se aproximou muito pouco do grupo. Em 2008, enviou o mais reconhecido especialista em proteínas tau, o neuropatologista Peter Davies, do Albert Einstein College of Medicine de Nova Iorque, para avaliar os trabalhos do grupo. Após avaliar o material, ele confimou que Omalu estava correto e resolveu se envolver nas pesquisas. Segundo Davies: "The credit must go to Bennet Omalu, because he first reported this and nobody believed him, nobody in the field, and I'm included in that. I did not think there was anything there. But when I looked at the stuff, he was absolutely right. I was wrong to be skeptical" (LASKAS, 2009, p. 22).

Apesar disso, Davies acreditava que o uso de esteróides é que seria a principal causa de ETC, uma conclusão diferente da de Omalu, mas que também não era muito útil para a NFL. Evidentemente, o relatório feito por Davies nunca foi divulgado pela NFL.

Assim, até hoje não há um reconhecimento, por parte da NFL, de que jogar futebol americano pode causar a doença descoberta por Omalu. Seu comitê continua fazendo pesquisas, uma vez que, segundo informam, haveria poucos dados clínicos sobre pessoas vivas. A isso, Bailes comentou:

I just don't understand why the NFL is doing this. You know, pick up a textbook. Here's The Neuropathology of Dementia. It describes, in great detail, tau pathology. There's a whole chapter here about trauma causing dementia. That's why this is very quixotic to me that's there's even any resistance. It's wellknown that brain trauma is a risk for dementia. Why are we arguing this? Why can't we accept this and move on and try to prevent it? (LASKAS, 2009, p. 24)

Entretanto, em apenas 7 (sete) anos desde a morte de Webster, Omalu (com o auxílio dos demais) já havia provado 17 (dezessete) casos da doença em atletas que haviam sofrido colisões na cabeça (especialmente jogadores de futebol americano). Em 2015, quando do falecimento de outro jogador do hall da fama, Frank Gifford, mais um caso de ETC foi confirmado.

\footnotetext{
${ }^{13}$ Único instituto do mundo com fins não lucrativos dedicado ao estudo da memória humana e doenças que afetam a memória. Informações disponíveis em http://www.brni.org/. Acesso em: 25 mar. 2016.
} 
Além disso, em abril de 2015, a NFL fez um acordo em um processo judicial que tramitava desde 2013, pagando indenizações a jogadores aposentados que haviam sofrido doenças neurológicas que somavam US\$1.000.000.000,00 (um bilhão de dólares) ${ }^{14}$.

Apesar do aparente avanço, Omalu continua a sofrer em razão de sua descoberta, como ele mesmo declarou: "My life has not changed. This has never been about me. My life changed in 2005 when I published that paper [on Webster having CTE]. I'm still suffering from that. All I'm asking now is that people should leave me alone ${ }^{15}$ ".

Diante dessa realidade, passa-se a análise do caso com base em aspectos das Teoria da Justiça de John Rawls.

\section{Segunda parte: Análise da história apresentada sob a ótica da Teoria da Justiça}

Segundo Rawls, verdade e justiça andam em paralelo: a verdade seria a primeira das virtudes do sistema dos pensamentos, e a justiça seria a primeira das virtudes das instituições sociais. Desta forma, uma teoria que não seja verdadeira deve ser rejeitada e uma instituição que não seja justa, ainda que seja bem organizada e eficiente, deve ser reformulada ou abolida.

Partindo, então, da premissa de que a descoberta de Omalu é uma verdade não reconhecida pela NFL, passa-se a análise da história anteriormente descrita.

\subsection{A NFL como instituição social}

Segundo Rawls, as instituições sociais distribuem direitos e deveres fundamentais e determinam a divisão de vantagens decorrentes da cooperação social, sendo a constituição política e os arranjos econômicos e sociais as instituições mais importantes.

Assim, de acordo com Rawls, instituição é um sistema público de normas que define cargos e funções com seus direitos e deveres. Tais normas determinam as ações permitidas e proibidas, bem como estipulam penalidades e defesas, caso ocorram violações. Rawls então diz serem exemplos de instituições os jogos e ritos, mercados e sistemas de propriedades.

Neste sentido, o presente trabalho considera a NFL como uma instituição social por ser a NFL definida por determinado sistema de normas e os atos por ela especificados que são regularmente realizados segundo um entendimento público de que se deve obedecer às suas

\footnotetext{
${ }^{14}$ Conforme divulgado no artigo NFL Concussion Lawsuit Settlement: What 'Frontline' CTE Data Means For The Appeal Process. Disponível em: http://www.ibtimes.com/nfl-concussion-lawsuit-settlement-what-frontline-cte-datameans-appeal-process-2104528. Acesso em 26 mar. 2016.

${ }^{15}$ OMALU, B. Entrevista concedida à revista TIME. Nova Iorque, EUA, 22 dez. 2015. Disponível em: http://time.com/4158140/concussion-film-bennet-omalu-cte-nfl/. Acesso em: 07 mar. 2016.
} 
normas. Assim, as convenções do futebol americano, vigiadas e ditadas pela NFL, são tratadas como um conjunto de normas que a elevam ao nível de instituição social.

De acordo com Rawls, a organização das instituições sociais em um esquema único de cooperação é objeto primeiro dos princípios da justiça social. Deste modo, todos os envolvidos com a NFL seriam parte de um acordo, tendo o direito e o dever de saber o que as normas atinentes lhes garantem e lhes exigem, assim como garantem e exigem direitos e deveres dos demais envolvidos.

A divulgação das normas pela NFL é o que permite aos envolvidos saber as limitações de conduta esperadas e quais as atividades permissíveis, ou seja, as expectativas mútuas partem de um fundamento comum.

Quando se existe uma informação - como a da existência da ETC - conhecida por apenas uma parte dos envolvidos (no caso, os dirigentes da NFL e o Comitê de Traumas ao Cérebro da NFL), necessário avaliar se a apropriação de tal informação por apenas parte dos membros da instituição seria legítima. Para tanto, importa verificar se tais membros estariam retendo a informação de modo estratégico, buscando tirar o melhor proveito para a instituição.

Isto é, supondo que os dirigentes da NFL e o Comitê estivessem efetivamente investigando a doença, enquanto não houvesse comprovação de que a prática do futebol americano seria capaz de causar tal malefício, não divulgar tal informação poderia ser uma estratégia legítima, pois evitaria questionamentos sobre a segurança do esporte que trariam prejuízos imensuráveis à NFL.

Um exemplo que confirma o que foi dito acima é que, caso a NFL reconhecesse que a prática do futebol americano causa ETC, as indenizações devidas aos jogadores de futebol americano aposentados ou debilitados seriam muito maiores, afetando substancialmente sua lucratividade - isto considerando que há coerência por parte da NFL na aplicação das regras acerca das indenizações.

Assim, acreditando-se que a NFL é uma instituição, supõe-se que ela possui uma estrutura básica de normas e que tais normas obedecem a uma concepção de justiça. Além disso, sendo uma instituição, é de se esperar que a NFL, na aplicação das próprias normas, age de maneira imparcial e coerente.

Entretanto, podem ocorrer injustiças quando seus participantes - no caso os dirigentes e o Comitê anteriormente mencionado - deixam de aderir às leis e às interpretações apropriadas ao tomar decisões. Neste sentido, caso a conduta da NFL em relação à ETC não seja justificável por uma estratégia legítima, podemos considerá-la uma instituição injusta. 
Afinal, se considerarmos que a ETC é uma realidade, enquanto não a reconhece, a NFL deixa de buscar tratamento adequado, não permite aos jogadores avaliar o risco de sua profissão, não concede indenizações adequadas que permite aos jogadores ter uma vida digna, isto é, não alivia o sofrimento dos jogadores e, portanto, não melhora a qualidade de vida da população, em claro desvio das normas existentes.

Portanto, até que ponto os dirigentes e o Comitê da NFL (e, assim, a própria NFL) agiram de maneira legítima e justificável, sem prejuízo às expectativas dos demais envolvidos, é uma questão de justiça que precisa ser analisada.

Se a reatividade dos dirigentes e o Comitê tiver como único propósito preservar seus cargos e salários - ou seja, proteger seus benefícios pessoais em detrimento do benefício de todos -, a conduta é injustificável e, portanto, injusta. Por outro lado, e como dito acima, se for parte de uma estratégia legítima para preservar a própria NFL, enquanto instituição, é uma medida justa.

Passa-se então a análise do papel da justiça de John Rawls aplicado ao caso, para verificarmos se a conduta da NFL diante a descoberta da ETC foi justa ou injusta.

\section{2. $\underline{\text { O papel da justiça de John Rawls aplicado ao caso }}$}

Segundo John Rawls, justiça é a distribuição equitativa de direitos e obrigações, sendo seus dois princípios norteadores a liberdade e a igualdade. $\mathrm{O}$ desafio da justiça, então, seria equilibrar esses dois princípios, buscando como resultado uma sociedade bem ordenada, em que a justiça não abandona a perseguição da verdade, há uma forte coordenação, evitando que a sociedade fique partida e há estabilidade e eficiência nos atos das instituições sociais. Dados esses conceitos, passa-se a analisar a conduta da NFL diante da descoberta da ETC.

Anos atrás, a indústria do cigarro passava pela mesma crise que passa hoje a NFL: reconhecer os seus próprios malefícios. Evidentemente, aqueles que fumam, assim como aqueles que são fãs de futebol americano sentiram-se igualmente ofendidos. Há no ser humano um sentimento bastante reativo a qualquer novidade que desafie sua estabilidade.

Entretanto, como leciona Rawls, a verdade e a justiça não aceitam compromissos. Isso se justifica por serem a verdade e a justiça virtudes primeiras das atividades humanas e, assim, parâmetros fundamentais para o sucesso da vida em sociedade.

Assim, acreditando-se que a ETC é uma realidade e que, de fato, a prática do futebol americano pode causar tal doença, como vem comprovando Omalu e toda a comunidade médica americana, indaga-se: a atitude da NFL diante da descoberta de Omalu é uma atitude 
justa? Qual o papel da justiça nesse caso? Por que seria necessário buscar a verdade e em que medida essa busca retira o sentimento de injustiça?

Primeiramente, deve ser avaliado se haveria, por parte da NFL, uma conduta obrigatória, ou seja, um dever para com os jogadores de futebol. Como instituição social, a NFL possui, efetivamente, a obrigação de assistir os jogadores, cooperando com sua dignidade e melhoria do seu bem estar - o que, por conseguinte, reforça a necessidade da NFL de cooperar para que a sociedade não perca equilíbrio (já que a morte indigna de todos os jogadores, traz dor e sofrimento às famílias, além de pôr em risco todos os envolvidos).

Como comentado no item anterior, o reconhecimento da doença e divulgação clara a seu respeito somente poderiam ser negados pela NFL se houvesse uma estratégia legítima. Não é o que se observa no presente caso. Pelo contrário. A insistência dos dirigentes e Comitê da NFL em negar a doença e marginalizar as pesquisas médicas a seu respeito mostram claramente que tal conduta está eivada de interesses outros que não se coadunam com os princípios de justiça de John Rawls.

Assim, percebe-se uma clara violação, por parte da NFL, ao sistema de cooperação clamado por Rawls: se a NFL, enquanto liga de futebol americano mais poderosa do mundo, não busca a melhoria da qualidade de vida dos jogadores a ela vinculados, entende-se que há um grave conflito de interesses que viola os preceitos básicos da vida em sociedade. Logo, a atitude da NFL é uma atitude injusta.

Diante disso, é necessário um remédio justo para coibir o conflito. Mas seria a indenização pecuniária suficiente para reparar os malefícios identificados por Omalu? Evidente que não. No entanto, se a justiça, enquanto conceito ético-filosófico, não é suficiente para corrigir a injusta atitude da NFL, o judiciário (aplicador da justiça material) ocupa o papel de mitigador dos malefícios causados por tal atitude e as indenizações, ainda que tardiamente, aparecem como medida de justiça.

Entretanto, numa convicção pública de justiça, não parece correto deixar que os jogadores fiquem doentes e sofram gravemente, sem sequer permitir que suas famílias identifiquem a doença e tentem auxiliar os jogadores acometidos. Além disso, não reconhecer um problema e não buscar uma solução não só é ineficiente, pois permite a manutenção do virtuoso ciclo entre sucesso no esporte e morte trágica, como traz instabilidade às relações sociais envolvendo esses jogadores, a NFL, suas famílias e até mesmo ao judiciário - que acaba sendo sobrecarregado em virtude de uma conduta que poderia ser corrigida na origem. 
Não há nenhum aspecto positivo, portanto, na conduta da NFL, especialmente se forem considerados os preceitos da teoria de John Rawls.

A ausência de cooperação por parte da NFL, portanto, leva uma doença grave ao desconhecimento, afetando a coordenação, eficiência e estabilidade necessárias para que uma sociedade seja justa. Não permite sequer que um jovem, ao ingressar na carreira de jogador, tome uma decisão consciente em relação à carreira que deseja seguir.

Deste modo, respondendo ao terceiro questionamento, se a NFL resolvesse, efetivamente, buscar a verdade, o sentimento de injustiça não permaneceria, uma vez que uma atitude positiva da NFL poderia reduzir a reatividade dos fãs de futebol americano, reduzindo o preconceito sofrido por Omalu, auxiliando o avanço das pesquisas e ampliando o bem-estar dos jogadores - por exemplo, se a NFL reconhecesse a doença e buscasse um remédio ou até mesmo sua cura, as pesquisas lideradas por Omalu poderiam estar muito mais avançadas e os jogadores poderiam estar sendo muito melhor acolhidos por toda a sociedade.

Portanto, o papel da justiça ao presente caso é claro: reduzir (ou até mesmo eliminar) o injusto sofrimento dos envolvidos.

\subsection{Aspectos utilitaristas identificados no presente caso}

Uma vez considerado que a conduta da NFL diante da descoberta da ETC foi uma conduta injusta, interessante comentar alguns aspectos do presente caso que remetem ao conceito do utilitarismo e por que razão tal conceito é afastado da concepção de justiça aceita no presente trabalho.

A ideia principal do utilitarismo clássico é que a sociedade está ordenada de forma justa "quando suas principais instituições estão organizadas de modo a alcançar o maior saldo líquido de satisfação, calculado com base na satisfação de todos os indivíduos que a ela pertencem" (Rawls, 2008, p. 27).

Assim, para o utilitarista não importa o modo como a soma das satisfações se distribui entre os indivíduos, tampouco como cada pessoa distribui suas satisfações ao longo do tempo. A distribuição correta é sempre aquela que produz saldo de satisfação máxima, de modo que os ganhos maiores de alguns compensam as perdas de outros, ou seja, a violação dos direitos de alguns pode ser justificada pelo bem maior partilhado pelos demais.

Muito próxima à concepção utilitarista é a convicção do médico que, como narrado na primeira parte, pede a Omalu que encerre as pesquisas e nada mais publique, de modo a preservar os benefícios sociais trazidos pelo futebol americano. Isto é, o sofrimento dos 
jogadores seria compensado com todos os benefícios que o esporte traria à sociedade. Um cálculo evidentemente utilitarista. Mas por que refutar o utilitarismo?

Como ensina John Rawls:

(...) na ausência de impulsos benevolentes fortes e duradouros, um homem racional não aceitaria uma estrutura básica só porque eleva ao máximo a soma algébrica das vantagens, fossem quais fossem as consequencias permanentes dessa estrutura sobre seus próprios direitos e interesses fundamentais (Rawls, 2008, p. 17).

Isto é, não parece provável que pessoas que se consideram iguais, em uma posição original, onde desconhecem qualquer realidade, aceitariam correr o risco de ter uma vida com perspectivas inferiores para que outros pudessem ter vantagens que, somadas, compensassem suas perdas. Ou seja, o utilitarismo não conversa com os conceitos de cooperação social alguém poderia estar perdendo e isso ser indiferente, se os ganhos de outros indivíduos, descontadas tais perdas, tivessem saldo líquido positivo.

No caso em comento, se o médico estivesse correto, o sofrimento dos jogadores que são acometidos por ETC e de suas famílias seria justificável e legítimo, uma vez que o esporte traria benefícios sociais que compensariam tal sofrimento.

Entretanto, o cálculo utilitarista simplifica demasiadamente as relações sociais e impede o progresso, pois elimina as chances de debates e questionamentos, impedindo que novos conceitos sejam aplicados.

Ao retomar os questionamentos feitos na introdução deste trabalho, quanto às razões pelas quais o ser humano é reativo às novidades, pode-se aferir que tal reatividade é resultado de um cálculo utilitarista e muitas vezes individualista: se determinado indivíduo está satisfeito com a posição social que ocupa, não haveria razão para que ele refletisse sobre algo novo que de maneira direta não lhe trará nenhuma vantagem.

Pode ter sido esse o raciocínio dos dirigentes e Comitê da NFL, pois, ao reconhecer a relação entre o ETC e a prática do futebol americano, eles reconheceriam não ter sido a NFL a primeira a descobrir uma doença que estaria matando seus ídolos, colocariam em risco os próprios cargos e funções e lidariam com um futuro incerto, posto que, assim como toda novidade, não se há evidências empíricas de seu resultado concreto.

Assim, embora o utilitarismo ainda seja aplicado nas sociedades atuais, refuta-se seu uso, por considerar que não é uma teoria que traz medidas justas para os indivíduos, pois afasta a cooperação social e, consequentemente, a necessária equidade entre eles. 


\subsection{A decisão racional de se tornar um jogador}

Por fim, o último aspecto do presente caso que deve ser abordado diz respeito à necessária decisão racional que um indivíduo precisa ter antes de se tornar um jogador de futebol americano.

Julian Bailes, ao tratar desse tema, comenta:

Here we have a multibilliondollar industry. Where does their responsibility begin? Say you're a kid and you sign up to play football. You realize you can blow out your knee, you can even break your neck and become paralyzed. Those are all known risks. But you don't sign up to become a braindamaged young adult. The NFL should be leading the world in figuring this out, acknowledging the risk. They should be thanking us for bringing them this research. Where does their responsibility begin? (LASKAS, 2009, p. 16)

Para a doutrina de Rawls, aceita e aplicada no presente trabalho, há um argumento intuitivo de que o destino das pessoas deve depender de suas escolhas, e não das circunstâncias em que por acaso se encontram.

Como podem os jovens tomar uma decisão bem informada a respeito de se tornarem jogadores de futebol americano se a NFL não lhes permitir conhecer os riscos de tal atividade?

Em entrevista ao Public Broadcasting Service, Omalu faz as seguintes considerações acerca da ausência de conhecimento dos riscos da ETC pelos indivíduos que decidem jogar futebol americano ${ }^{16}$ :

Some people have paid prices, their lives. Some people, while adding value to entertain us, while contributing to the American experience, pay the ultimate price with their lives, and unfortunately were not aware while they were entertaining us that they were slowly losing their lives.

If you are a military person and you sign up to become a member of the military, you know there is a reasonable chance that you will die, that you could suffer permanent body harm, but a football player signs up at 4 years old -- which is very sad.

The child of 6, 7 years old signs up. He is told it is a sport; there are benefits; you're a football player. You're a college football player, there are some benefits. As a professional player you're going to make money. But nobody tells them that you're also losing your life as you do that.

Assim, a apropriação da informação acerca da ETC por apenas membros da NFL e, pior ainda, o descaso com que a instituição trata o assunto, não se coadunam com os princípios de justiça social de John Rawls, especialmente o princípio da liberdade.

\footnotetext{
${ }^{16}$ OMALU, B. Entrevista concedida ao Public Broadcasting Service. 25 mar. 2013. Disponível em: http://www.pbs.org/wgbh/pages/frontline/sports/league-of-denial/the-frontline-interview-dr-bennet-omalu/. Acesso em: 12 mar. 2016.
} 
Para John Rawls, garantir acesso igual a um mesmo sistema de liberdades amplas é objetivo maior da justiça social, logo, impedir aos jogadores tomarem uma decisão consciente sobre a profissão que querem seguir, reduz sua liberdade de escolha e, portanto, torna-se medida injusta.

A ordem pública, que deveria ser preservada por instituições sociais, como a NFL, deve privilegiar a liberdade igual de consciência para que os indivíduos possam tomar decisões racionais e bem informadas. Certamente não é o que a NFL vem fazendo.

Nem mesmo o lançamento do filme parece ter conduzido à NFL à cooperação. Na mesma entrevista, Omalu foi perguntado se o filme foi uma forma de redenção e ele afirmou, sem hesitação, que não, comentando em seguida:

It was more a validation of players who suffered from this disease. A validation for the player's families. Many said we wish we had known sooner. Wives said they thought their husbands were bad men. They just did not know how sick they were ${ }^{17}$.

Portanto, o lançamento do filme Concussion, levando a ETC ao conhecimento de mais pessoas, acabou validando a necessidade em divulgar a informação para permitir uma decisão racional por parte dos futuros jogadores e suas famílias.

Assim, após o filme, Omalu tem recebido mais e mais cartas de antigos jogadores de futebol americano. Ele espera que a NFL e o Governo Federal Americano estabeleçam centros de pesquisas por todo o país para que estudem a doença mais profundamente e possibilitem que uma informação, cada vez mais apurada, seja divulgada aos cidadãos ${ }^{18}$.

\section{Conclusão}

Diante dos fatos narrados e das considerações feitas acerca da teoria de John Rawls, é possível concluir que a NFL é uma instituição social e, como tal, deve afastar-se de cálculos utilitaristas, buscando justiça social por meio da manutenção da estabilidade das relações existentes entre os envolvidos.

Para tanto, a NFL deve privilegiar a busca da verdade, o que precisa fazer com eficiência. E tal eficiência, nesse caso, significaria (i) a não apropriação da informação acerca da ETC e sua conexão com a prática do futebol americano por apenas parte dos indivíduos que compõem a NFL e, ainda, (ii) a proatividade da NFL em manter os jogadores (e

\footnotetext{
${ }^{17}$ OMALU, B. Entrevista concedida ao Public Broadcasting Service. 25 mar. 2013. Disponível em: http://www.pbs.org/wgbh/pages/frontline/sports/league-of-denial/the-frontline-interview-dr-bennet-omalu/. Acesso em: 12 mar. 2016.

${ }^{18}$ O Instituto Nacional de Doenças Neurológicas conseguiu, recentemente, levantar R \$16,000,000.00 (dezesseis milhões de dólares) para estudar a ETC em pessoas vivas. A pesquisa envolverá cinquenta pesquisadores de dezessete instituições.
} 
potenciais jogadores) bem informados acerca dos riscos que podem estar correndo ao tomarem a decisão de seguir carreira no futebol americano.

Infelizmente, o que se observa é exatamente o oposto. A NFL não só se recusou, durante anos, a reconhecer a existência da doença, como agiu de forma completamente preconceituosa com aquele que a descobriu.

A instituição permitiu (e continua permitindo) que os jogadores alcancem o estado de absoluta invalidez, deixando suas famílias à própria sorte, recusando-se, ainda, a, arbitrariamente, pagar-lhes uma indenização adequada que lhes permita ter um fim de vida com dignidade.

Além disso, não há que se falar em utilitarismo nesse caso, pois, em uma sociedade justa, as liberdades fundamentais são inquestionáveis e os direitos garantidos pela justiça não estão sujeitos a negociações políticas nem ao cálculo dos interesses sociais.

Portanto, considerando que a NFL é uma instituição social atuando de forma injusta, pois não busca aliviar o sofrimento dos jogadores, de suas famílias e até mesmo de Omalu, e sequer permite o conhecimento pelos jogadores para que tomem uma decisão bem informada, tenta-se responder o problema apontado no presente trabalho: por que sociedades consideradas desenvolvidas ainda se deparam com situações gravemente injustas?

Certamente a resposta não é direta e objetiva. Como apontado ao longo do texto, é comum ao ser humano reagir de forma negativa às novidades, pois desconhece suas consequencias. No caso dos dirigentes da NFL e do seu Comitê, assumir uma ligação entre a ETC e a prática do esporte poderia resultar no seu próprio fracasso profissional. Outro aspecto é que a descoberta da doença por um nigeriano ofendeu o ego de toda a comunidade médica.

Isto é, apesar de toda a evolução e desenvolvimento, ainda há no indivíduo certos receios que dificultam o progresso social, mesmo nos Estados Unidos da América, onde viveu John Rawls.

Assim, em resposta ao problema apresentado, acredita-se que, pela natureza reativa do ser humano - especialmente instigado por sua intuição utilitarista e por seu receio quanto às consequencias daquilo que é novo - é que se observa que, mesmo em sociedades desenvolvidas, ainda ocorrem casos de grave injustiça.

No caso narrado neste trabalho, em especial, a injustiça vem sendo corrigida principalmente pela atuação de um indivíduo que não possui a mesma cultura (e, portanto, possui outros conceitos éticos-filosóficos) dos demais envolvidos. 
Assim, feitas as ponderações de cunho filosófico e ético acerca da história envolvendo Omalu e a NFL, acredita-se que a aplicação da Teoria de John Rawls ao caso pode trazer soluções morais que estimulam consequencias práticas como (i) ser a NFL obrigada a reconhecer a existência da doença e assumir uma posição de liderança frente às pesquisas, de modo a buscar sua cura ou, no mínimo, tratamento adequado, (ii) ser a sociedade norteamericana compreensiva com a doença, reduzindo o sofrimento das famílias e dos jogadores, e (iii) ter o judiciário amplo conhecimento a respeito do tema, fazendo com que os julgamentos a esse respeito passem a ter mais coerência e, portanto, se alcance uma maior estabilidade nas relações sociais.

\section{REFERÊNCIAS BIBLIOGRÁFICAS}

Blanchette Rockefeller Neurosciences Institute to Collaborate with Top Brain Injury Group. 2 set. 2009. Disponível em: http://www.brni.org/news/articles/Blanchette_Rockefeller_ Neurosciences_Institute_to_Collaborate_wi,3.aspx. Acesso em 20 mar. 2016.

BARRABI, Thomas. NFL Concussion Lawsuit Settlement: What 'Frontline' CTE Data Means For The Appeal Process. 18 set. 2015. http://www.ibtimes.com/nfl-concussion-lawsuit-settlementwhat-frontline-cte-data-means-appeal-process-2104528. Acesso em 26 mar. 2016.

LASKAS, Jeanne Marie. Bennet Omalu, Concussions, and the NFL: How One Doctor Changed Football Forever. Disponível em: http://www.gq.com/story/nfl\%ADplayers\%

ADbrain\%ADdementia\%ADstudy\%ADmemory\%ADconcussions. Acesso em: 07 mar. 2016.

RAWLS, John. Uma Teoria da Justiça. $3^{\text {a }}$ ed. - São Paulo : Martins Fontes, 2008.

OMALU, Bennet. Dr. Bennet Omalu. The Frontline Interviews. Public Broadcasting Service. 25 mar. 2013. Disponível em: http://www.pbs.org/wgbh/pages/frontline/sports/league-of-denial/thefrontline-interview-dr-bennet-omalu/. Acesso em: 12 mar. 2016.

OMALU, Bennet. Concussion Expert: Over 90\% of NFL Players Have Brain Disease. TIME. 22 dez. 2015. Disponível em: http://time.com/4158140/concussion-film-bennet-omalu-cte-nfl/. Acesso em: 07 mar. 2016.

OMALU, B. Bennet Omalu, doctor who raised alarm bells about NFL head injuries, on racism in U.S. science. Washington Post. 29 dez. 2016. Disponível em: https://www.washingtonpost.com/news/to-your-health/wp/2015/12/29/bennet-omalu-doctor-whoraised-alarm-bells-about-nfl-head-injuries-on-racism-in-u-s-science/. Acesso em: 20 mar. 2016.

Um Homem Entre Gigantes. Direção de Peter Landesman. EUA: Sony Pictures, 2015. (2h3min), color., legendado.

https://www.ucdmc.ucdavis.edu/pathology/our_team/faculty/OmaluB.html. Acesso em: 07 mar. 2016.

https://en.wikipedia.org/wiki/Bennet_Omalu. Acesso em: 07 mar. 2016. 